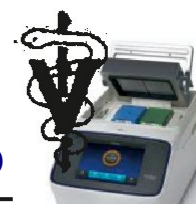

\title{
Pathologic Diagnosis of Infectious Bursal Disease Outbreak In Vaccinated 3- week Old Pullet Chicks on A Small Scale Commercial Poultry Farm In Leleyi-kwali, Abuja, Nigeria: A Case Report
}

\author{
Abalaka S. E.. ${ }^{{ }^{*}}$, Sani N. A. ${ }^{1}$, Idoko S. I. ${ }^{1}$, Tenuche O. Z. ${ }^{1}$, Ejeh S. A ${ }^{2}$, Sambo, K. W. ${ }^{3}$, Sa'idu \\ L. ${ }^{3}$, Shoyinka S. V. O. ${ }^{4}$ and Ameh J. A. \\ ${ }^{1}$ Department of Veterinary Pathology, University of Abuja, Nigeria \\ ${ }^{2}$ Department of Veterinary Physiology and Biochemistry, University of Abuja, Nigeria \\ ${ }^{3}$ Veterinary Teaching Hospital, Ahmadu Bello University, Zaria, Nigeria \\ ${ }^{4}$ Department of Veterinary Pathology and Microbiology, University of Nigeria, Nsukka, Nigeria \\ ${ }^{5}$ Department of Veterinary Microbiology, University of Abuja, Nigeria \\ Accepted January, 2019 and Published February, 2019
}

\begin{abstract}
A sudden mortality which lasted for seven days with the peak on the third day, was investigated in vaccinated 3-week old pullet chicks. Signs of depression, ruffled feathers, sneezing, huddling together and pasted vents with about 50\% morbidity were observed. While chicks were off feed Vaccination history against Marek's and Newcastle diseases was reportedly up to date. The first dose of Infectious Bursal Disease (IBD) vaccination was done 12 days before the onset of the outbreak preparatory to the second dose. Detailed post mortem examinations showed multifocal petechial to ecchymotic haemorrhages on the breast and thigh muscles with swollen, oedematous and haemorrhagic bursa of Fabricius in affected chicks. The bursa of Fabricius showed diffuse lymphoid depletion with multifocal vacuolations and eosinophilic cystic follicles. Similar diffuse lymphoid depletion and cytoplasmic vacuolation with fibrinous exudation were also present in the spleen. Serological analysis revealed $88.23 \%$ IBD antibody positive sera in affected pullets 16 days after cessation of mortality. A diagnosis of Infectious Bursal Disease outbreak was made based on the observed pathological presentations along with the clinical signs, typical spiked mortality pattern, and serological titre. These findings highlighted the need for continuous pathological investigations as a ready diagnostic tool in vaccinated and unvaccinated pullet chicks in Nigeria where Infectious bursal disease has become endemic.
\end{abstract}

Key words: Infectious Bursal Disease, Chicks, Pathology, Serology, Vaccinated pullet Chicks

\footnotetext{
*Corresponding author's

email: samson.abalaka@uniabuja.edu.ng

Tel.: +2348025269585
} 


\section{INTRODUCTION}

Infectious Bursal Disease (IBD) is an acute and highly contagious viral disease of young, and sometimes older chickens, causing high morbidity and mortality $[1,2]$. The disease is characterized mainly by lesions in the Bursa of Fabricius and other organs like the spleen, thymus, skeletal muscles and kidneys, followed by immunosuppression $[3,4]$, which predisposes birds to other infections and reduce their ability for adequate humoral responses to vaccinations [5]. The disease was first discovered in Gumboro area of Delaware, USA in 1962, hence, the name "Gumboro disease" [6]. However, the disease was first reported in South Western Nigeria in 1973 [7] and later confirmed in the South Eastern part of the country in 1975 [8]. While chickens are highly susceptible to the disease, turkeys and ducks show minimal or no susceptibility to the disease under natural conditions [9]. About 2-3 vaccinations are usually done against IBD in Nigeria depending upon the disease dynamics within the area. Although there are reports of Gumboro Disease outbreaks in immunized chickens in Nigeria [2,10] and other parts of the world $[11,12]$, information on pathological aspects of the disease outbreak in pullet chicks after first IBD vaccination as a prompt on-thefield diagnostic tool is scanty, hence the need for this case report. This study aimed to report a case of pathological diagnosis of IBD outbreak in vaccinated 3-week old pullet chicks on a small scale commercial poultry farm in LeleyiKwali, Abuja, Nigeria.

\section{CASE PRESENTATION}

An outbreak of IBD occurred in a batch of 3week old pullet chicks on a small scale commercial poultry farm located at LeleyiKwali, Abuja, Nigeria with a cumulative mortality of $35.99 \%$. The chicks were reportedly vaccinated against Marek's disease and Newcastle disease at day old and had their first IBD vaccine administered orally at day- 9 of age using a live attenuated intermediate strain of the virus, which was to be repeated $\left(2^{\text {nd }}\right.$ dose) on day-22 of age thereafter. The administered IBD vaccines were purchased from a Veterinary Drugs Vendor and transported on ice packs prior to reconstitution and administration. The chicks had all the routine antibiotics, deworming and anticoccidial medications before the onset of the outbreak. History revealed that affected chicks became progressively inactive with raised feathers and were huddling together a day before the earlier scheduled administration of the second dose of the vaccination, which was consequently put off because of the prevailing condition. The chicks were raised on the floor in an open-sided pen within the immediate vicinity of two other open-sided pens housing about 1500 laying chickens (45 week and 91 week old) in two rows of 3-tier cages whose litter were evacuated every three days. About $50 \%$ of affected chicks were anorexic, depressed and were sneezing and had ruffled feathers and pasted vents while huddling together close to the source of heat. Mortality rose and declined within seven days with peak mortality on the $3^{\text {rd }}$ day of the onset of mortality.

A detailed post mortem examination was conducted on 20 dead and moribund pullet chicks presented on the $3^{\text {rd }}$ day of the outbreak. Liver, kidney, spleen, lungs, heart and bursa of fabricius samples were collected and immediately fixed in $10 \%$ neutral buffered formalin. They were processed and stained with haematoxylin and eosin according to standard procedure [13]. The extent of damage in the 
bursa of Fabricius and the spleen were scored [14]. Blood was collected from the basilic or wing vein of 20 randomly selected live pullet chicks from the flock 16 days after cessation of mortality and dispensed into plain sample bottles. The Sample were then transported on ice packs to the Avian Unit, Veterinary Teaching Hospital, Ahmadu Bello University, Zaria, Nigeria for serum separation and IBD virus antibody evaluation using the Agar Gel Precipitation Test (AGPT) as earlier described [15]. The extent of damage in the bursar of Fabricius and the spleen were scored as previously describes [16] as shown in Tables 1 and 2. The incidence of gross pathological changes were calculated as percentages while mean $( \pm$ SEM) of lesion scores were obtained using GraphPad Prism software programme (GraphPad Prism Version 6, San Diego, USA).

\section{RESULTS}

Carcasses, which were in fair to good body conditions were moderately dehydrated. There were multifocal petechial to ecchymotic haemorrhages on breast and thigh muscles (70.0\%) of affected chicks as shown in Fig. 1. The lungs were slightly congested $(15.0 \%)$ with mucus in the trachea (45.0\%). Proventricular glands were markedly swollen and haemorrhagic $(45.0 \%)$. About $70.0 \%$ of the liver was diffusely congested with engorged gall bladder $(55.0 \%)$. The spleen $(15.0 \%)$ and the lungs $(15.0 \%)$ were diffusely congested. Kidneys were markedly enlarged and mottled in appearance (30.0\%) as shown in Fig. 2, while evidence of moderate catarrhal exudatation (30.0\%) was seen in intestines of affected chicks. The bursa of Fabricius was markedly swollen with gelatinous exudation on serosal surfaces (Fig.2) while incised bursar had creamy cheesy exudates and/or multifocal haemorrhages (85.0\%) as shown in Fig 3.

There was generalized lymphoid depletion within the medullar and cortex of bursal follicles clearly demarcated by prominent zone of epithelium in between them. This is in addition to the presence of prominent reticular cells, oesinophilic cystic cavities within the medulla and vacuolations within bursal follicles and the presence of prominent interseptal and inter-follicular oedema with plicated bursal epithelial cells in the bursa of Fabricius (Fig. 4). Diffuse lymphoid depletion within the germinal follicles and the periarteriolar sheath with prominent reticular cells was observed in the spleen. This was in addition to multifocal splenic parenchymal disruptions by fibrinous exudation and vacuolations. The liver showed diffuse congestion and cytoplasmic microvacuolations in addition to the presence of multifocal areas of hepatic necrosis with fibrinous exudation. Diffuse congestion and perivascular oedema with parabronchi alveolar haemorrhage were seen in the lungs (Fig. 5) while multifocal mononuclear cellular infiltrations were also evident within the myocardium (Fig. 6). There was marked glomerular cellularity in affected kidneys. The bursa of Fabricius and spleen lesion scores were $4.55 \pm 0.13$ and $3.65 \pm 0.13$, respectively. A total of $88.23 \%$ of the sera $(15 / 17)$ were positive for IBD antibodies based on the AGPT.

\section{DISCUSSION}

The diagnosis of IBD was made based on gross 
and histopathological presentations along with the sudden onset, moderate morbidity, spiking (pyramidal) mortality pattern and sharp recovery from the disease within seven days of the outbreak, which are characteristics of IBDV infection as previously suggested [17]. Although haemorrhages at the proventricular and ventricular junction with congested proventricular glands were earlier reported $[17,18]$, only swollen and haemorrhagic proventricular glands were observed in this case. The observed bursal and splenic lymphoid cellular depletions were due to lymphoid necrosis with the resultant hyperplasia and prominence of reticular cells although this feature is characteristic of other viral infections [19]. The micro-vacuolations that coalesced to form bursal follicular cystic cavities and the widened inter-septal and inter-follicular spaces due to oedema and proliferating fibroplasia were associated with declining inflammatory reactions in the disease condition [20]. Similar widened inter-septal and inter-follicular spaces with loose inflammatory cells in affected bursa of Fabricius have been reported [21]. The plicated bursal epithelial cells, which might become glandular with mucus producing cells, were due to epithelial cells proliferation $[19,20]$. Although a researcher has reported no lung lesion in previous work on IBD infection [18], perivascular oedema and parabronchi alveolar haemorrhages were observed in this case. The obtained lesion scores were indicative of marked bursal and splenic tissue damage in affected pullet chicks.
Outside the possibility of infection with a variant field strain of the virus, the disease outbreak in this particular flock might have been due to vaccine failure occasioned by improper storage, transportation or improper, reconstitution and administration of the vaccine. Similar cases of IBD outbreaks have been reported in vaccinated chicken flocks $[17,22]$. Although AGPT test was positive for IBD 16 days after cessation of mortality indicative of the presence of IBD antibody, paired sera sampling at the beginning and at the end of the outbreak would have been ideal to help in the determination of the actual fold increase, especially as the maternally derived antibody levels and possible response to the initial vaccination was not monitored before the onset of the outbreak. However, the presence of any of these antibodies would have conferred protection against the disease outbreak in the first instance. This case report was another attempt at diagnosing IBD using pathological presentations as a prompt on-the-field diagnostic tool. This is even as there is an increasing need for constant survey of circulating field IBD viral strain in Nigeria in order to verify if vaccinal strains are capable of adequately protecting vaccinated chicks against field infection or not.

\section{ACKNOWLEDGEMENT}

The authors acknowledge the immense contribution of Mr. F. Akolo to the work in terms of looking after the birds and assisting in samples collection. 


\section{Conflict of interest}

The authors declare no conflict of interest as the work was privately funded by all authors.

\section{REFERENCES}

1. Van den Berg T. P., Etarradossi N., Toquin D. and Meulemans G. (2000). Infectious Bursal Disease (Gumboro disease). Revue scientifique et technique, 19(2): 509-543.

2. Shekaro A. and Josiah I. E. (2015). Infectious bursal disease outbreak in fifteen weeks old pullets in Kaduna, Nigeria. Journal of Animal Production Advances, 5 (3): 636-644.

3. McFeraran J. B. (1993). Infectious bursal disease. In: McFerran J. B., McNulty M. S. (Eds.). Virus infections of birds. Elsevier Science, Amsterdam, Pp. 213-228.

4. Lukert P. D. and Saif Y.M.(1997). Infectious bursal disease. In: Calnek B. W., Barnes H. J., Beard C. W., McDonald L. R., Saif Y.M.(Eds.). Diseases of Poultry. $10^{\text {th }}$ Edition. Iowa State University, Ames, Pp. 721-738.

5. Shane S. (1997). Infectious Bursal Disease: USA: The poultry disease handbook. American Soybean Association, Pp. 57-61.

6. Cosgrove A. S. (1962). An apparently new disease of chickens: Avian nephrosis. Avian Diseases, 6:385-389.

7. Ojo M. O., Oduye O. O., Noibi L. M. and Idowu A. L. (1973). Gumboro-like disease in Nigeria. Tropical Animal Health and Production, 5 (1): 52-56.

8. Onunkwo O. (1975). An outbreak of infectious bursal disease (IBD) of chickens in Nigeria. Veterinary Record, 97(22): 433.

9. Kegne T. and Chanie M. (2014). Review on the incidence and pathology of infectious bursal disease. British Journal of Poultry Sciences, 3 (3): 6877.

10. Owoade A. A., Mulders M. N., Kohnen J., Ammerlaan W. and Muller C. P. (2004). High sequence diversity in infectious bursal disease virus serotype 1 in poultry and turkey suggests WestAfrican origin of very virulent strains. Archives of Virology, 149 (4): 653-672.

11. Çeribaşi A. O., Bulut H., Gülaçti I., Eröksüz Y. and Bolat Y. (2007). Presence of a very virulent genotype of infectious bursal disease virus in vaccinated layer hens in Turkey. Turkish Journal of Veterinary and Animal Science, 31 (2): 105-111

12. Islam M. N., Rashidi S. M. H., Hoque M. F., Juli M. S. B. and Khatu M. (2008). Pathogenecity of IBDV related to outbreak in the vaccinated flocks and the causes of vaccination failure. Journal of Innovation and Development Strategy, 2:22-30.

13. Bancroft J. D. and Cook H. C. (1994). Manual of histological techniques and their diagnostic application. London: Churchill Livingstone, Pp. 289-305.

14. Krishnamoorthy P., Vaiaramuthu S., Balachandran C. and Muralimanohar B. (2007). Pathology of lymphoid organs in chlorpyriphos and T-2 toxin fed 
broiler chicken. International Journal of Poultry Science, 6(1): 71-76.

15. Castello L., Martinez, B. 1. and Heronodez K. (1987). Comparison of the agar gel precipitation, virus neutralization and enzyme-linked immunosorbent assay in the determination of antibodies to infectious bursal disease virus. Veterinaria México, 18:317-323.

16. Krishnamoorthy P., Vairamuthu S., Balachandra C. and Muralimanohar B. (2007). Pathology of lymphoid organs in Chlorpyrifos and T-2 toxin fed broiler Chicken. International Journal of Poultry Science, 6(1): 71 - 76

17. Aliyu H. B., Sa'idu L., Jamilu A., Andamin A. D. and Akpavie S. O. (2016). Outbreaks of virulent infectious bursal disease in flocks of battery cage brooding system of commercial chickens. Journal of Veterinary Medicine 2106; Article ID 8182160, 7 $\begin{array}{lllll}p & a & g & e & s\end{array}$ http://dx.doi.org/10.1155/2016/8182160

18. Okoye J. O. A. (1985). Histopathology of infectious bursal disease in nonlymphoid organ of chickens. Revue d'elevage et de médicine vétérinaire des pays tropicaux, 38 (3):229-234.

19. Cheville N. F. (1967). Studies on the pathogenesis of Gumboro disease in the bursa of Fabricius, spleen, and thymus of the chicken. American Journal of Pathology, 51 (4): 527-551.

20. Eterradossi N. and Saif Y. M. (2008). Infectious bursal disease. In: Saif Y. M. (Ed.). Diseases of Poultry. $12^{\text {th }}$ edition. Ames: Blackwell Publishing, Ames, Pp. 185-208.

21. Abdul-Aziz T. and Fletcher O. J. (2016). In: Abdul-Aziz T., Fletcher O. J., Barnes H. J. Avian Histopathology. $4^{\text {th }}$ edition. American Association of Avian Pathologist Inc., Florida, Pp. 35-40.

22. Abdu P. A. (1986). Infectious bursal disease immunization failures in chickens in Nigeria. Tropical Animal Health and Production, 18: 123-125.

Table 1: Lesion score of the bursa of Fabricius

\begin{tabular}{lc}
\hline Description & $\begin{array}{c}\text { Lesion } \\
\text { score }\end{array}$ \\
\hline Normal follicles. & 0 \\
Follicles showing scattered lymphoid depletion in the cortex and medulla. & 1 \\
$\begin{array}{l}\text { Follicles showing lymphoid depletion and necrosis in less than 50 per cent of } \\
\text { cells and mild interfollicular fibrosis. }\end{array}$ & 2 \\
$\begin{array}{l}\text { Follicles showing lymphoid depletion and necrosis in more than 50 per cent of } \\
\text { cells and moderate interfollicular fibrosis. }\end{array}$ & 3 \\
$\begin{array}{l}\text { Follicles showing glandular epithelial transformation and cystic changes with } \\
\text { marked interfollicular fibrosis. }\end{array}$ & \\
Atrophy of follicles with marked fibroplasia & 4 \\
\hline
\end{tabular}


Table 2: Lesion score of the spleen

\begin{tabular}{ll}
\hline Description & $\begin{array}{l}\text { Lesion } \\
\text { score }\end{array}$ \\
\hline Normal follicles. & 0 \\
Isolated lymphoid cell depletion and necrosis & 1 \\
Depletion and necrosis in less than 50 per cent of lymphoid cells with mild reticular 2 \\
cell hyperplasia & 3 \\
Depletion and necrosis in more than 50 per cent of lymphoid cells with marked & 3 \\
\hline
\end{tabular}

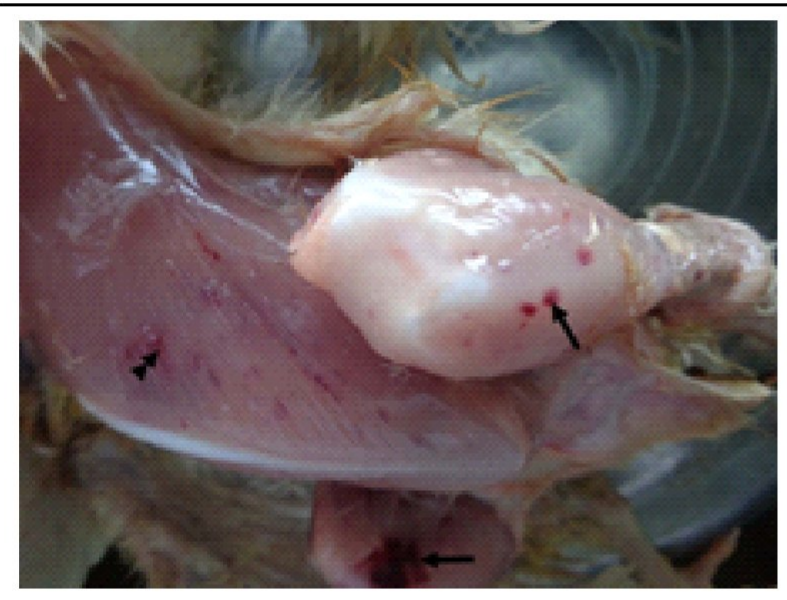

Figure 1: The photograph of the breast and thigh muscles of an infectious bursal disease vaccinated 3-week old pullet chick showing ecchymotic haemorrhages on the breast muscle (double arrow heads) and thigh muscles (arrow).

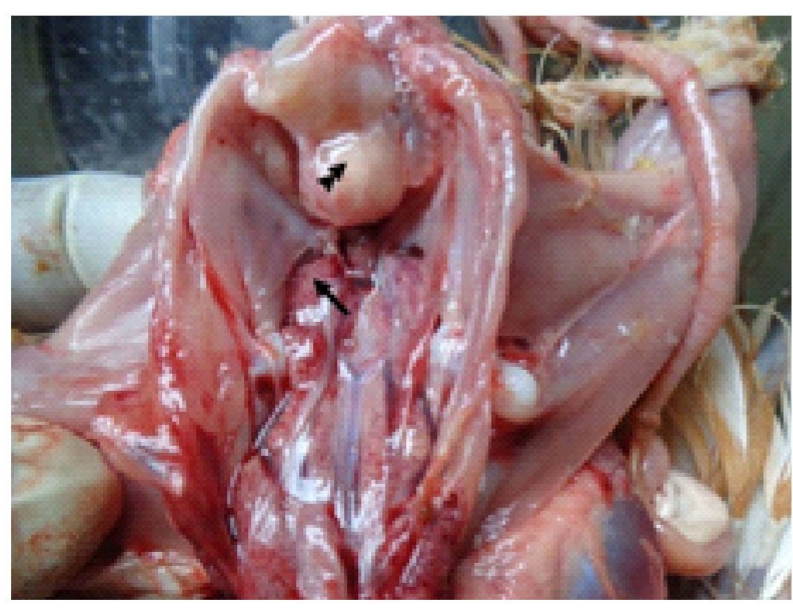

Figure 2: The photograph of the bursa of Fabricius and kidney of an infectious bursal disease vaccinated 3-week old pullet chick showing swollen and mottled grey kidney (arrow) with the swollen, oedematous and gelatinous material covered bursa of Fabricius (double arrow heads).

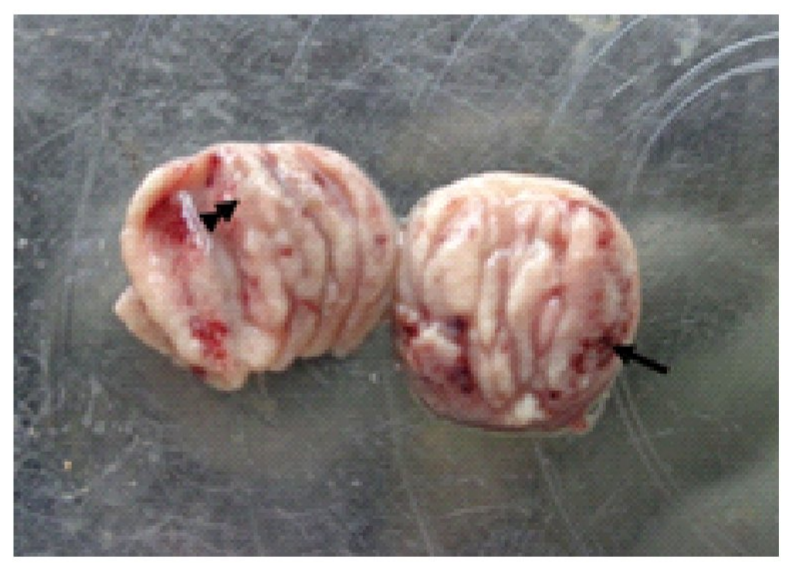

Figure 3: The photograph of the bursa of Fabricius of an infectious bursal disease vaccinated 3-week old pullet chick showing haemorrhagic bursal lamellar (arrow) and bursal lamellar caseation (double arrow heads). 


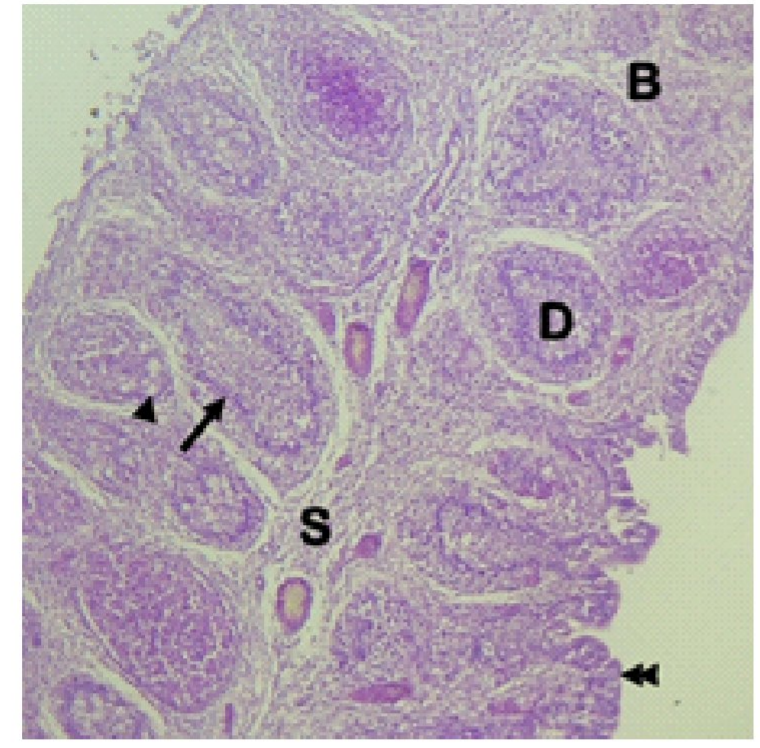

Figure 4: The photomicrograph of the bursa of Fabricius of an infectious bursal disease vaccinated 3-week old pullet chick showing diffuse lymphoid cells depletion (D) with prominent zone of epithelial cells between the follicular cortex and the medulla (arrow), vacuolations within the lymphoid follicles (arrow head), widened inter-septal space (S) and widened inter-follicle space (B) with plicated bursal epithelial cells (double arrow heads). H \& E x 75

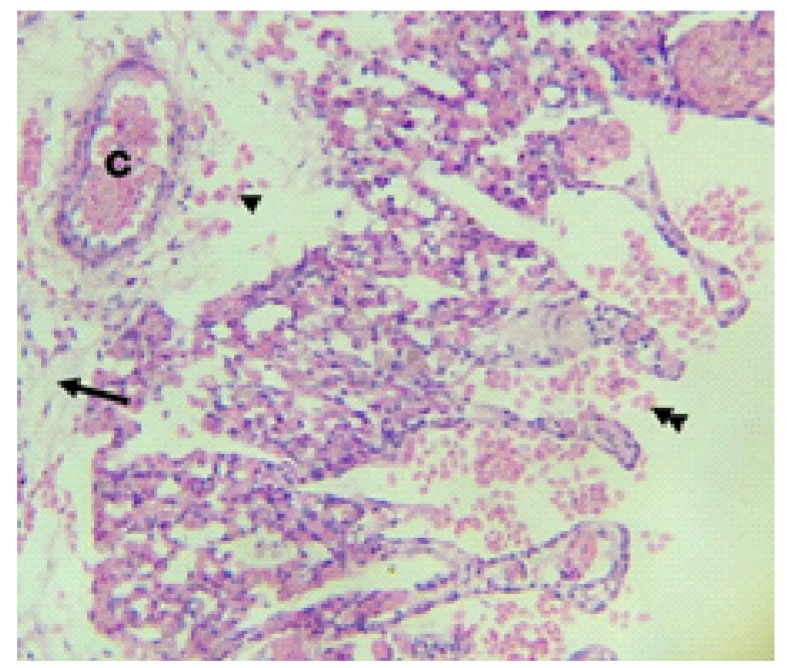

Figure 5: The photomicrograph of the lung of an infectious bursal disease vaccinated 3-week old pullet chick showing marked congestion (C) and perivascular oedema (arrow) with perivascular haemorrhage (arrow head) and parabronchi haemorrhages (double arrow heads). H \& E x 307

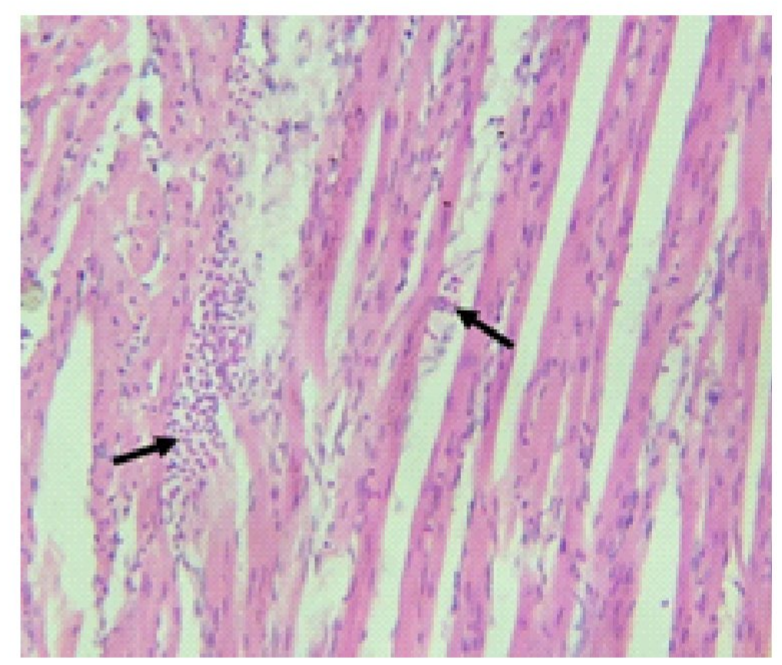

Figure 6: The photomicrograph of the heart of an infectious bursal disease vaccinated 3-week old pullet chick showing multifocal mononuclear cellular infiltration of the myocardium (arrows). H \& E x 342 